\title{
GAMBARAN FOTO TORAKS PADA PENDERITA DEWASA DENGAN \\ DIAGNOSIS KLINIS DIABETES MELITUS YANG DISERTAI TUBERKULOSIS PARU DI BAGIAN/SMF RADIOLOGI \\ FK UNSRAT BLU RSUP PROF. Dr. R. D. KANDOU MANADO PERIODE 1 JANUARI 2011 - 31 DESEMBER 2011
}

\author{
${ }^{1}$ Muhammad Rizal Ismail \\ ${ }^{2}$ Ramli Hadji Ali \\ ${ }^{3}$ Elvie Loho
}

\author{
${ }^{1}$ Kandidat Skripsi Fakultas Kedokteran Universitas Sam Ratulangi Manado \\ ${ }^{2}$ Bagian Radiologi Fakultas Kedokteran Universitas Sam Ratulangi Manado \\ Email : rizal.pengmas_SMFKUnsrat@yahoo.com
}

\begin{abstract}
Diabetes is a major threat to human health in the $21^{\text {st }}$ century. WHO to estimate that in 2025 , number of people with diabetes over of 20 years will develop to 300 million people. Diabetes mellitus is also a disease that can lead to many complications one of them pulmonary tuberculosis, this complication be enforced with radiodiagnostic like thorax photo. The purpose of this study is to know about description of thorax photo in adult patients with a clinical diagnosis of diabetes mellitus with pulmonary tuberculosis in Department/SMF Radiology Faculty of Medicine UNSRAT BLU RSUP Prof. dr. R. D. Kandou Manado period on $1^{\text {st }}$ January $2011-31^{\text {st }}$ December 2011. The study design was a retrospective descriptive study. The data are from request form sheet and radiographic response in the Department of Radiology and processed in descriptive. Results of this study indicate the number of patients with radiologic diagnosis of diabetes mellitus who accompanied pulmonary tuberculosis as many as 90 patients. Most cases are in the age of $56-65$ years $(41.11 \%)$ with the man that is equal to $53.33 \%$. With the results of thorax photo in infiltrate view the highest $30.00 \%$. The conclusion is description of thorax photo in adult patients with a clinical diagnosis of diabetes mellitus with pulmonary tuberculosis were fewer compared to those without pulmonary tuberculosis with the highest infiltrates view.
\end{abstract}

Keywords: Diabetes mellitus, thorax photo, pulmonary tuberculosis

\begin{abstract}
Abstrak: Diabetes adalah salah satu ancaman utama bagi kesehatan umat manusia pada abad ke-21. WHO membuat perkiraan bahwa pada tahun 2025 jumlah pengidap diabetes di atas umur 20 tahun akan membengkak menjadi 300 juta orang. Diabetes melitus juga merupakan suatu penyakit yang bisa menimbulkan banyak komplikasi salah satunya tuberkulosis paru, komplikasi ini diketahui dengan menggunakan radiodiagnostik seperti foto toraks. Tujuan penelitian ini adalah untuk mengetahui tentang gambaran foto toraks pada penderita dewasa dengan diagnosis klinis diabetes melitus yang disertai tuberkulosis paru di Bagian/SMF Radiologi FK UNSRAT BLU RSUP Prof. Dr. R. D. Kandou Manado periode 1 januari 2011 - 31 desember 2011. Desain penelitian ini adalah penelitian retrospektif yang bersifat deskriptif. Data berupa lembaran permintaan dan jawaban foto toraks di Bagian Radiologi dan diolah dalam bentuk deskriptif. Hasil penelitian ini menunjukkan jumlah penderita dengan diagnosis radiologis diabetes melitus yang disertai tuberkulosis paru sebanyak 90 penderita. Kebanyakan kasus adalah pada umur 56 - 65 tahun $(41,11 \%)$ dengan lakilaki yaitu sebesar $53,33 \%$. Dengan hasil gambaran foto toraks terbanyak pada gambaran Infiltrat yaitu $30,00 \%$. Kesimpulannya ialah dari hasil gambaran foto toraks pada penderita dewasa dengan diagnosis klinis diabetes melitus yang disertai tuberkulosis paru ternyata lebih sedikit dibandingkan dengan yang tanpa tuberkulosis paru dengan gambaran terbanyak yaitu infiltrat.
\end{abstract}

Kata Kunci: Diabetes melitus, foto toraks, tuberkulosis paru 


\section{Latar Belakang}

Terdapat berbagai macam penyakit degeneratif di dunia ini. Diantara penyakit degeneratif tersebut, diabetes adalah salah satu diantara penyakit tidak menular yang akan meningkat jumlahnya di masa yang akan datang. Diabetes adalah salah satu ancaman utama bagi kesehatan umat manusia pada abad ke-21. World Health Organization (WHO) membuat perkiraan bahwa pada tahun 2000 jumlah pengidap diabetes di atas umur 20 tahun berjumlah 150 juta orang dan dalam kurun waktu 25 tahun kemudian, pada tahun 2025, jumlah itu akan membengkak menjadi 300 juta orang. ${ }^{1}$

Pada konsensus pengelolaan Diabetes Melitus (DM) berbagai penelitian epidemiologis di Indonesia didapatkan prevalensi DM sebesar 1,5 - 2,3\% pada penduduk usia lebih dari 15 tahun, bahkan pada suatu penelitian epidemiologis di Manado, didapatkan prevalensi DM 6,1\% dan DM dapat menyerang warga segala lapisan umur dan sosial ekonomi. DM juga seringkali tidak terdeteksi dan dikatakan onset atau mulai terjadi diabetes adalah 7 tahun sebelum diagnosis ditegakkan, sehingga morbiditas dan mortalitas dini terjadi pada kasus yang tidak terdeteksi ini. ${ }^{2,3}$

Diabetes melitus merupakan penyakit degeneratif yang dapat di diagnosis dengan beberapa pemeriksaan seperti anamnesis, pemeriksaan fisik dan pemeriksaan penunjang seperti pemeriksaan glukosa darah di laboratorium klinik. ${ }^{3}$ Dan juga bisa ditunjang dengan pemeriksaan radiologi pada organ-organ yang dicurigai terkena DM. ${ }^{4}$ Oleh karena DM merupakan suatu permasalahan penting yang bisa terkena pada setiap manusia maka kita perlu mendiagnosis DM secara dini.

Diabetes melitus juga merupakan suatu penyakit yang bisa menimbulkan banyak komplikasi dan juga faktor risiko seperti hipoglikemia, ketoasidosis diabetik, neuropati sampai tuberkulosis paru. Tuberkulosis Paru (TB Paru) merupakan suatu penyakit infeksi yang bisa ditegakkan dengan melakukan beberapa pemeriksaan penunjang, salah satunya dengan radiodiagnostik. ${ }^{5}$

Tuberkulosis paru masih merupakan masalah kesehatan utama di negara sedang berkembang, termasuk Indonesia, di mana sebagian besar penduduknya hidup di pedesaan dengan derajat kesehatan yang masih rendah. Di Indonesia TB paru merupakan penyebab kematian nomor empat setelah penyakit infeksi saluran napas bawah, diare dan penyakit jantung koroner. Berbagai upaya perlu dilakukan untuk menurunkan prevalensi TB paru ini, salah satu adalah usaha menemukan penderita yaitu dengan meningkatkan kemampuan menegakkan diagnosis, agar dapat diberikan obat anti tuberkulosis (OAT) yang tepat. Berdasarkan hasil pemeriksaan foto toraks dapat dicurigai apakah suatu lesi pada paru merupakan TB aktif atau inaktif, selain itu dapat digunakan untuk menyingkirkan kemungkinan positif palsu pada hasil tes tuberkulin dengan tanpa gejala klinis. Selain itu, pemeriksaan foto toraks dapat digunakan untuk kasus TB yang meragukan, yaitu dengan menggunakan foto kontrol apakah terjadi perbaikan, menetap atau perburukan pada penderita TB paru. Meskipun demikian pemeriksaan foto toraks tidak untuk diagnosis tetapi penunjang dalam menegakkan diagnosis TB paru. ${ }^{6}$

Dengan semakin bertambahnya angka kesakitan DM dengan faktor risiko TB Paru serta banyaknya permintaan pemeriksaan dengan menggunakan foto toraks di Instalasi Radiodiagnostik BLU RSUP Prof. Dr. R. D. Kandou Manado dan belum pernah dilakukan penelitian seperti ini sebelumnya, maka mendorong penulis untuk meneliti lebih lanjut tentang gambaran foto toraks pada penderita 
dewasa dengan diagnosis klinis diabetes melitus yang disertai tuberkulosis paru di Bagian/SMF Radiologi FK UNSRAT BLU RSUP Prof. Dr. R. D. Kandou Manado pada 1 januari 2011 - 31 desember 2011.

\section{Rumusan Masalah}

Bagaimana gambaran foto toraks pada penderita dewasa dengan diagnosis klinis diabetes melitus yang disertai tuberkulosis paru di Bagian/SMF Radiologi FK UNSRAT BLU RSUP Prof. Dr. R. D. Kandou Manado periode 1 januari 2011 - 31 desember 2011 ?

\section{Metode Penelitian}

Penelitian ini merupakan penelitian deskriptif retrospektif dengan memanfaatkan data sekunder. Data berupa lembaran permintaan dan jawaban hasil foto toraks pada penderita dengan diagnosis klinis diabetes melitus di Bagian/SMF Radiologi FK UNSRAT BLU RSUP Prof. Dr. R. D. Kandou Manado periode 1 januari 2011 - 31 desember 2011. Penelitian ini merupakan penelitian deskriptif retrospektif dengan memanfaatkan data sekunder. Data berupa lembaran permintaan dan jawaban hasil foto toraks pada penderita dengan diagnosis klinis diabetes melitus di Bagian/SMF Radiologi FK UNSRAT BLU RSUP Prof. Dr. R. D. Kandou Manado periode 1 januari 2011 - 31 desember 2011. Populasi pada penelitian ini yaitu semua lembaran permintaan dan jawaban penderita diabetes melitus di Bagian RSUP Prof. Dr. R. D. Kandou Manado periode 1 januari 2011 - 31 desember 2011, sedangkan sampelnya yaitu semua lembaran dan jawaban penderita dengan diagnosis klinis diabetes melitus yang disertai tuberkulosis paru di Bagian/SMF Radiologi FK UNSRAT BLU RSUP Prof.
Dr. R. D. Kandou Manado periode 1 januari 2011 - 31 desember 2011.

\section{Hasil Penelitian}

Berdasarkan hasil penelitian retrospektif gambaran foto toraks pada penderita dewasa dengan diagnosis klinis diabetes melitus yang disertai tuberkulosis paru di Bagian/SMF Radiologi FK UNSRAT BLU RSUP PROF. Dr. R. D. KANDOU Manado periode 1 januari 2011 - 31 desember 2011, didapatkan hasil sebagai berikut.

1. Distribusi penderita dengan diagnosis klinis diabetes melitus yang disertai tuberkulosis paru yang dilakukan pemeriksaan foto toraks di Bagian/SMF Radiologi FK UNSRAT BLU RSUP Prof. Dr. R. D. Kandou Manado periode 1 januari 2011 - 31 desember 2011 berdasarkan hasil pemeriksaan foto toraks.

Dari 295 penderita diabetes melitus, ditemukan sebanyak 90 orang penderita yang disertai tuberkulosis paru $(30,51 \%)$ dan 205 penderita DM tanpa disertai tuberkulosis paru $(69,49 \%)$.

Tabel 2. Distribusi sampel berdasarkan hasil pemeriksaan foto toraks.

\begin{tabular}{ccc}
\hline $\begin{array}{c}\text { Hasil } \\
\text { Pemeriksaan } \\
\text { Foto Toraks }\end{array}$ & $\begin{array}{c}\text { Jumlah } \\
\text { Penderita } \\
(\mathrm{n})\end{array}$ & $\begin{array}{c}\text { Persentase } \\
(\%)\end{array}$ \\
\hline Gambaran & 90 & 30,51 \\
DM yang & & \\
disertai TB & 205 & 69,49 \\
Paru & & \\
Gambaran & & \\
DM tanpa & & \\
disertai TB & & \\
Paru & & \\
\hline Jumlah & 295 & 100 \\
\hline
\end{tabular}




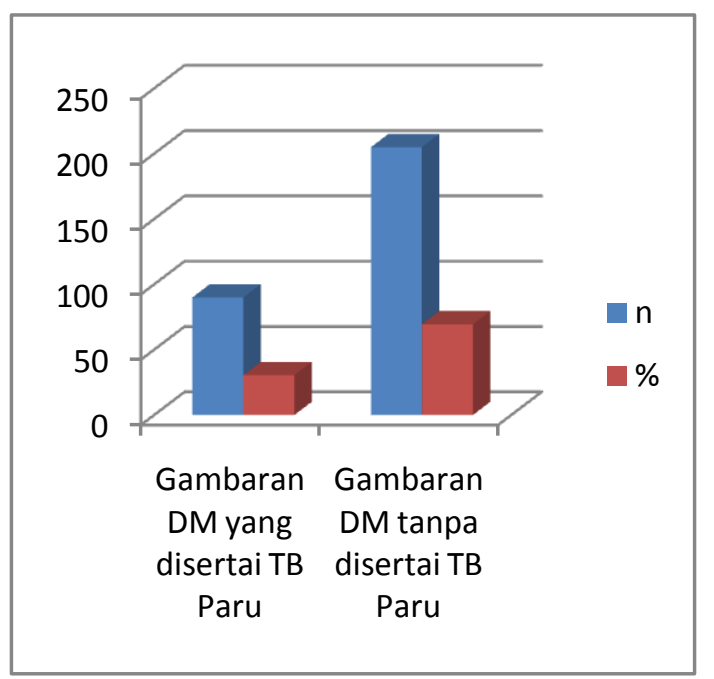

Grafik 1. Distribusi sampel berdasarkan hasil pemeriksaan foto toraks.

2. Distribusi penderita dengan diagnosis klinis diabetes melitus yang disertai tuberkulosis paru yang dilakukan pemeriksaan foto toraks di bagian Radiologi/SMF radiologi FK UNSRAT BLU RSUP PROF. Dr. R. D. KANDOU Manado periode 1 januari 2011 31 desember 2011 berdasarkan kelompok umur.

Dari 90 kasus diabetes melitus yang terjadi pada periode 1 januari 2011 - 31 desember 2011, terdapat sebanyak 1 orang penderita $(1,11 \%)$ pada kelompok umur 26 - 35 tahun, 9 orang penderita (10\%) pada kelompok umur 36 - 45 tahun, 26 orang penderita $\quad(28,89 \%) \quad$ pada kelompok umur 46 - 55 tahun, 37 orang penderita $(41,11 \%)$ pada kelompok umur 56 - 65 tahun, dan 7 orang pasien $(7,77 \%)$ pada kelompok umur $>65$ tahun.
Tabel 3. Distribusi sampel berdasarkan umur.

\begin{tabular}{ccc}
\hline $\begin{array}{c}\text { Umur } \\
\text { (tahun) }\end{array}$ & $\begin{array}{c}\text { Jumlah } \\
\text { Penderita } \\
(\mathrm{n})\end{array}$ & $\begin{array}{c}\text { Persentase } \\
(\%)\end{array}$ \\
\hline $26-35$ & 1 & 1.11 \\
\hline $36-45$ & 9 & 10.00 \\
\hline $46-55$ & 26 & 28.89 \\
\hline $56-65$ & 37 & 41.11 \\
\hline$>65$ & 17 & 18.89 \\
\hline Jumlah & 90 & 100.00 \\
\hline
\end{tabular}

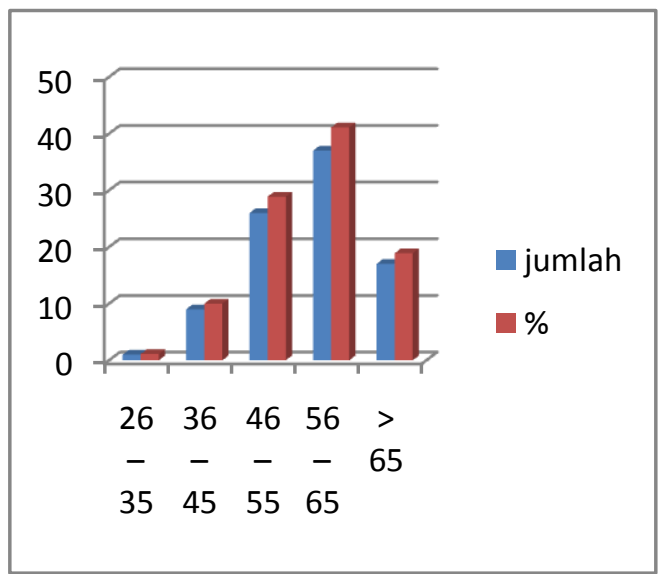

Grafik 2. Distribusi sampel berdasarkan kelompok umur.

3. Distribusi penderita dengan diagnosis klinis diabetes melitus yang disertai tuberkulosis paru yang dilakukan dengan pemeriksaan foto toraks di bagian Radiologi/SMF Radiologi FK UNSRAT BLU RSUP PROF. Dr. R. D. KANDOU Manado periode 1 januari 2011 - 31 desember 2011 berdasarkan jenis kelamin.

Dari 90 kasus diabetes melitus yang disertai tuberkulosis paru yang terjadi pada periode 1 januari 2011 - 31 desember 2011, ditemukan penderita laki-laki berjumlah 48 orang $(53,33 \%)$ dan penderita perempuan berjumlah 42 orang $(46,67 \%)$. 
Tabel 4. Distribusi sampel berdasarkan jenis kelamin.

\begin{tabular}{ccc}
\hline $\begin{array}{c}\text { Jenis } \\
\text { Kelamin }\end{array}$ & $\begin{array}{c}\text { Jumlah } \\
\text { Penderita } \\
(\mathrm{n})\end{array}$ & $\begin{array}{c}\text { Persentase } \\
(\%)\end{array}$ \\
\hline Laki - laki & 48 & 53,33 \\
\hline Perempuan & 42 & 46,67 \\
\hline Jumlah & 90 & 100 \\
\hline
\end{tabular}

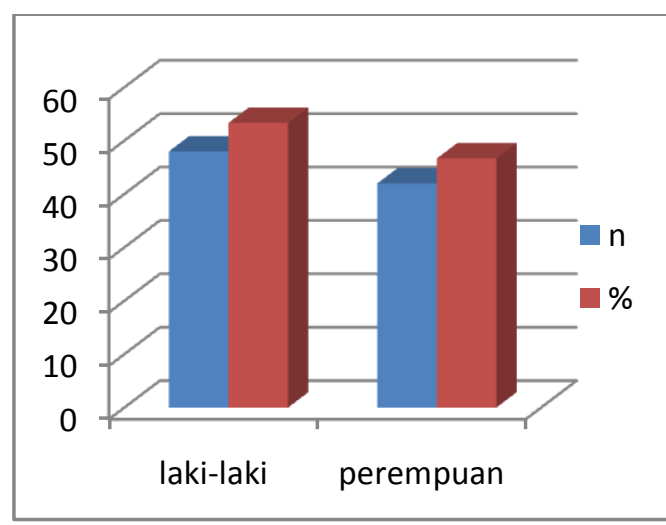

Grafik 3. Distribusi sampel berdasarkan jenis kelamin.

4. Distribusi penderita dengan diagnosis klinis diabetes melitus yang disertai tuberkulosis paru yang dilakukan pemeriksaan foto toraks di Bagian/SMF Radiologi FK UNSRAT BLU RSUP Prof. Dr. R. D. Kandou Manado periode 1 januari 2011 - 31 desember 2011 berdasarkan gambaran pemeriksaan foto toraks.

Dari 90 kasus diabetes melitus yang disertai tuberkulosis paru yang terjadi pada periode 1 januari 2011 - 31 desember 2011, ditemukan sebanyak 27 orang penderita dengan infiltrat $(30,00 \%), 6$ orang penderita dengan kalsifikasi $(6,67 \%), \quad 12$ orang penderita dengan infiltrat dan kalsifikasi $(5,56 \%)$, 5 orang penderita dengan infiltrat dan kavitas $(5,56 \%), \quad 19$ orang penderita dengan kalsifikasi dan efusi pleura $(21,11 \%), 7$ orang

penderita dengan infiltrat, kalsifikasi, dan fibrotik $(7,78 \%)$, serta 14 orang penderita dengan infiltrat dan penebalan $(15,56 \%)$.

\section{Tabel 5. Distribusi sampel berdasarkan gambaran foto toraks.}

\begin{tabular}{ccc}
\hline $\begin{array}{c}\text { Gambaran } \\
\text { Foto Toraks }\end{array}$ & $\begin{array}{c}\text { Jumlah } \\
\text { Penderita } \\
(\mathrm{n})\end{array}$ & $\begin{array}{c}\text { Persentase } \\
(\%)\end{array}$ \\
\hline Infiltrat & 27 & 30,00 \\
\hline Kalsifikasi & 6 & 6,67 \\
\hline $\begin{array}{c}\text { Infiltrat dan } \\
\text { kalsifikasi }\end{array}$ & 12 & 13,33 \\
\hline $\begin{array}{c}\text { Infiltrat dan } \\
\text { kavitas }\end{array}$ & 5 & 5,56 \\
\hline $\begin{array}{c}\text { Kalsifikasi } \\
\text { dan efusi } \\
\text { pleura }\end{array}$ & 19 & 21,11 \\
\hline $\begin{array}{c}\text { Infiltrat, } \\
\text { kalsifikasi, } \\
\text { dan fibrotik }\end{array}$ & 7 & 7,78 \\
\hline $\begin{array}{c}\text { Infiltrat dan } \\
\text { penebalan }\end{array}$ & 14 & 15,56 \\
\hline Jumlah & 90 & 100 \\
\hline
\end{tabular}

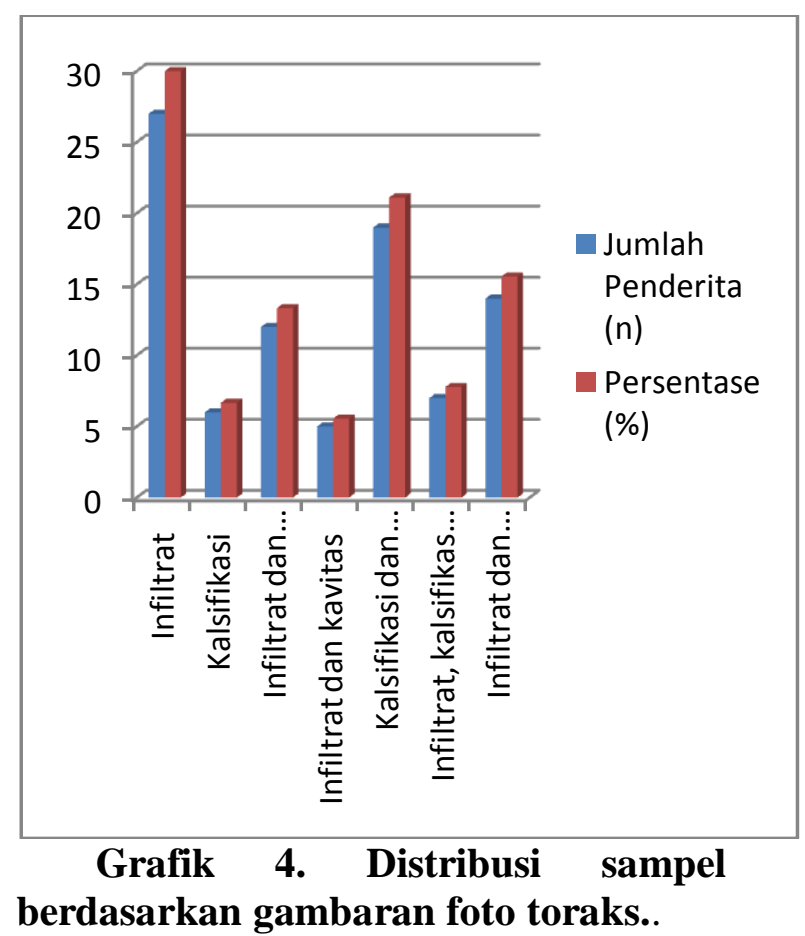




\section{Pembahasan}

Pada penelitian ini ditemukan sebanyak 295 kasus dengan diagnosis klinis diabetes melitus yang melakukan pemeriksaan foto toraks di bagian Radiologi/SMF Radiologi FK UNSRAT BLU RSUP Prof. Dr. R. D. Kandou Manado periode 1 januari 2011 - 31 desember 2011.

Berdasarkan hasil pemeriksaan foto toraks (Tabel 2) dari penelitian ini didapatkan jumlah penderita DM yang disertai tuberkulosis paru sebanyak 90 orang $(30,51 \%)$ dari 295 orang yang melakukan pemeriksaan foto toraks, sedangkan 205 orang $(69,49 \%)$ tidak terbukti tuberkulosis paru. Hal ini hampir sama dengan penelitian yang dilakukan Bacakoðlu et al. melakukan penelitian untuk melihat apakah diabetes melitus mempengaruhi manifestasi klinis dan radiologis tuberkulosis pada pejamu nonimunokompromais dan untuk melihat keterlibatan lapangan paru bawah. Dari penelitian tersebut didapatkan bahwa DM tidak mempengaruhi gejala, hasil bakteriologi, reaktivitas tuberkulin, dan lokalisasi infiltrat pada gambaran radiografi. $^{7}$ Hal ini dikarenakan pertumbuhan $M$. tuberculosis tidak langsung menyebar dengan cepat, tetapi membutuhkan waktu yang agak lama. Sehingga pada sebagian besar pasien belum ditemukan adanya TB Paru.

Berdasarkan kelompok umur (Tabel 3) dari penelitian ini didapatkan sebanyak 1 orang penderita $(1,11 \%)$ pada kelompok umur 26 - 35 tahun, 9 orang penderita (10\%) pada kelompok umur 36 - 45 tahun, 26 orang penderita $(28,89 \%)$ pada kelompok umur 46 - 55 tahun, 37 orang penderita $(41,11 \%)$ pada kelompok umur 56 - 65 tahun, dan 7 orang pasien $(7,77 \%)$ pada kelompok umur $>65$ tahun. Hal ini sedikit berbeda dengan penelitian yang dilakukan oleh Eli Juli Suryani Nasution, 2007 di RSUP H. Adam Malik Medan yang menyatakan bahwa terdapat 16 orang penderita $(17,2 \%)$ pada kelompok umur $<40$ tahun, 28 orang penderita $(29,8 \%)$ pada kelompok umur 41 - 50 tahun, 35 orang penderita $(37,2 \%)$ pada kelompok umur 51-60 tahun, 12 orang penderita $(12,8 \%)$ pada kelompok umur 61 - 70 tahun dan 3 orang penderita $(3,2 \%)$ pada kelompok umur $>70$ tahun. Ini membuktikan bahwa tidak di jumpai perbedaan pada umur 40 - 65 tahun. Jadi dari kedua penelitian ini tidak menunjukkan perbedaan yang begitu besar. Alasan lain juga karena pada usia lanjut, disamping fungsi sel beta lebih terganggu, juga pada usia lanjut umumnya sudah lama menderita DM serta kontrol DM biasanya labil. ${ }^{8}$

Berdasarkan jenis kelamin (Tabel 4) dari penelitian ini ditemukan bahwa penderita laki-laki berjumlah 48 orang $(53,33 \%)$ dan lebih banyak dibandingkan penderita perempuan yang berjumlah 42 orang $(46,67 \%)$. Hal yang sama juga didapat oleh Qazi M.A et al 2009 yang mengemukakan bahwa laki-laki lebih banyak terkena daripada perempuan. Hal ini biasanya dikarenakan faktor predisposisi dimana laki-laki lebih sering merokok dan bekerja diluar rumah dibandingkan perempuan. ${ }^{9}$

Berdasarkan gambaran foto toraks (Tabel 5) dari penelitian ini ditemukan bahwa sebanyak 27 orang penderita dengan infiltrat $(30,00 \%), 6$ orang penderita dengan kalsifikasi $(6,67 \%), 12$ orang penderita dengan infiltrat dan kalsifikasi $(5,56 \%), 5$ orang penderita dengan infiltrat dan kavitas (5,56\%), 19 orang penderita dengan kalsifikasi dan efusi pleura $(21,11 \%), 7$ orang penderita dengan infiltrat, kalsifikasi, dan fibrotik $(7,78 \%)$, serta 14 orang penderita dengan infiltrat dan penebalan $(15,56 \%)$. Hal ini sesuai kepustakaan yang ada yaitu terdapat adanya infiltrat, kavitas, efusi pleura, fibrotik, kalsifikasi dan penebalan pleura. ${ }^{6}$

\section{Kesimpulan}

Berdasarkan gambaran foto toraks pada penderita dewasa dengan diagnosis klinis 
diabetes melitus yang disertai tuberkulosis paru di Bagian/SMF Radiologi FK UNSRAT BLU RSUP Prof. Dr. R. D. Kandou Manado periode 1 januari 2011 31 desember 2011, dapat disimpulkan bahwa hasil pemeriksaan foto toraks pada penderita dewasa dengan diagnosis klinis diabetes melitus yang disertai tuberkulosis paru ternyata lebih sedikit dibandingkan dengan yang tanpa disertai tuberkulosis paru, pada penderita dewasa dengan diagnosis klinis diabetes melitus yang disertai tuberkulosis paru lebih banyak terkena pada usia 56 - 65 tahun, pada penderita dewasa dengan diagnosis klinis diabetes melitus yang disertai tuberkulosis paru ternyata laki-laki sedikit lebih banyak daripada perempuan, serta hasil pemeriksaan foto toraks pada penderita dewasa dengan diagnosis klinis diabetes melitus yang disertai tuberkulosis paru memberikan gambaran berupa infiltrat, kalsifikasi, infiltrat dan kalsifikasi, infiltrat dan kavitas, kalsifikasi dan efusi pleura, serta infiltrat, kalsifikasi dan fibrotik.

\section{Saran}

Sebaiknya orang dengan usia lanjut baik laki-laki maupun perempuan agar lebih sering memeriksakan kesehatan dirinya ke dokter terutama pemeriksaan foto toraks apabila orang tersebut menderita diabetes melitus agar bisa menghindari resiko terkena penyakit tuberkulosis paru serta bagi tenaga medis yang bergerak di bidang pelayanan rekam medik terutama di bagian Radiologi agar dapat melengkapi pencatatan hasil pemeriksaan baik foto toraks maupun pemeriksaanpemeriksaan lain. Supaya lebih mempermudah dalam hal memperoleh data yang akan digunakan untuk penelitian - penelitian selanjutnya.

Ucapan terima kasih ditujukan kepada dr. Julia Cori Matheos Lombo, SpP dan dr. Julied Dehoop, MPd,Ked selaku penguji 1 dan penguji 2 atas masukan dan saran dan kepada pihak-pihak yang secara langsung atau tidak langsung memberikan gagasan dan ide kepada penulis

\section{Daftar Pustaka}

1. Sudoyu S. Diabetes Melitus Di Indonesia. Buku Ajar Ilmu Penyakit Dalam Jilid III Edisi V. Jakarta: InternaPublising; 2009; Hal. 1874

2. Misnadiarly. Diabetes Mellitus: Gangren, Ulcer, Infeksi Edisi Pertama. Jakarta: Pusaka Populer Obor; 2006; Hal. 117-122

3. Purnamasari D. Diagnosis Dan Klasifikasi Diabetes Melitus. Buku Ajar Ilmu Penyakit Dalam Jilid III Edisi V. Jakarta: InternaPublising; 2009; Hal. 1880-1883

4. Kota S K, Jammula S, Tripathy P R. Mediastinal Widening In Asymptomatic Type 1 Diabetes Mellitus Patient. Journal of Diabetology. 2012; Hal. 1-4

Diunduh pada 23 desember 2012:

http://www.journalofdiabetology.org/Page s/Releases/PDFFiles/EIGHTISSUE/CR5-JOD-11-034.pdf

5. Mansjoer A, Triyanti K, Savitri R, Wardhani W I, Setiowulan W. Kapita Selekta Kedokteran Edisi Ketiga Jilid Pertama; 2001; Hal. 580

6. Perhimpunan Dokter Paru Indonesia. Tuberkulosis, Pedoman Diagnosis dan Penatalaksanaan di Indonesia, Citra Grafika, Jakarta: 2006.

7. Bacakoðlu F, Bapoðlu ÕK, Çok G, Sayiner A, Ate ${ }^{\mathrm{o}}$ M. Pulmonary Tuberculosis in Patients with Diabetes Mellitus.

Diunduh pada 1 januari 2013:

http://www.ncbi.nlm.nih.gov/pubmed/117 86714

8. Nasution E J S, Profil Penderita Tuberkulosis Paru dengan Diabetes Melitus Dihubungkan Dengan Kadar Gula Darah Puasa

Diunduh pada 2 januari 2013: http://repository.usu.ac.id/bitstream/12345 6789/6408/1/08E00064.pdf

9. M.A. Qazi et al. Radiological Pattern of Pulmonary Tuberculosis in Diabetes Mellitus.

Diunduh pada 2 januari 2013: 
http://kemu.edu.pk/annals/apr-jun2009/Radiological-Pattern-of-Pulmonary-
Tuberculosis.pdf 